\title{
La escisión entre la Ciencia Política y la realidad política: el caso de la Seguridad Democrática*
}

\author{
Carlos Andrés Ramírez González ${ }^{* *}$ \\ (cargindustries@gmail.com)
}

\author{
Andrea Stefanía Jerez Cantor ${ }^{* * *}$ \\ (stfsherry@hotmail.com)
}

Artículo de investigación recibido el 29/12/2014 y aprobado el 19/12/2014

Cómo citar este artículo:

RAMÍREZ, González Carlos Andrés y Andrea Stefanía Jerez Cantor (2014). "La escisión entre la Ciencia Política y la realidad política: el caso de la Seguridad Democrática”. En: Trans-pasado Fronteras, núm. 6, pp. 99-118. Cali, Colombia: Centro de Estudios Interdisciplinarios, Jurídicos, Sociales y Humanistas (CIES), Facultad de Derecho y Ciencias sociales, Universidad Icesi.

\begin{abstract}
Resumen
La política de seguridad democrática, adoptada por el Presidente Álvaro Uribe Vélez durante su periodo de gobierno, resultó en un viraje fundamental en los rumbos del país luego del fallido proceso de paz del gobierno Pastrana. En este sentido, el presente trabajo busca demostrar que la Ciencia Política abordó el fenómeno político en contravía con el curso de los hechos, de tal manera que mientras la política de Seguridad Democrática propugnaba por un aumento en la ofensiva militar, la visión desde la Ciencia Política

* Esta ponencia nace de la investigación Trayectorias de la Ciencia Política en Colombia: la influencia de los fenómenos políticos en el desarrollo disciplinar entre 1968 y 2012. Universidad Sergio Arboleda.

** Estudiante de Política y Relaciones Internacionales de la Universidad Sergio Arboleda, noveno semestre. Asistente de investigación en el proyecto "Avatares investigativos y formativos de la Ciencia Política en Colombia: hacia una revisión de la disciplina en su periodo de consolidación (1995-2010)”.

*** Estudiante de Política y Relaciones Internacionales de la Universidad Sergio Arboleda, Séptimo semestre. Pertenece al semillero del Grupo de Investigación Política y Sociedad.
\end{abstract}


se concentraba en la manera de llegar a unos diálogos de paz o una salida concertada al conflicto. Esto, por tanto, se puede traducir en un rechazo al punto de vista preponderante y a una postura alternativa en el estudio de la realidad política nacional. Para demostrar lo anterior, se realiza una revisión documental aplicada a artículos académicos en cuatro revistas de Ciencia Política del país: Análisis Político, Colombia Internacional, Papel Político y Estudios Políticos durante el periodo de publicación de 2002 a 2012.

Palabras clave:

Seguridad democrática, desarrollo disciplinar, paz, conflicto, contexto político

\section{Introducción}

La construcción de conocimiento académico siempre ha traído, necesariamente, la creación de interrogantes y la discusión de hechos que a diario llevan a nuestra sociedad a volver sobre sí misma. Cuestiones como la rigurosidad científica, la objetividad siempre exigida al investigador y lo estricto de metodologías establecidas hacen creer que, en realidad, el estudio de los hechos políticos está escindido directamente de la construcción de los mismos. Básicamente, una ciencia que no participa dentro de su objeto de estudio.

Sin embargo a lo anterior, muchos autores han reconocido lo inevitable de hacer política desde la Ciencia Política. Ravecca (2010) como otros, han encontrado que en sí mismo el hecho de crear conocimiento, de generar centros de pensamiento y de estudiar a profundidad los hechos políticos generan un acción política que interfiere directamente con el mundo social en el cual estamos inmersos. Escribir desde la derecha o desde la izquierda, como dice Ravecca, implica necesariamente tomar una decisión política mucho más allá de que la dinámica de la ciencia exija estimaciones lejanas al objeto de estudio. En términos generales, el trabajo de Ravecca muestra que más allá de simplemente estudiar lo político, el trabajo académico crea en sí mismo ambientes y hechos políticos que tienen experiencias, críticas y apoyos para con el mundo que, supuestamente según muchos autores de la academia norteamericana debería motivar la Ciencia Política y sus publicaciones (Vromen, 2010).

Para otros autores como Barrientos del Monte (2013) la construcción de conocimiento desde la Ciencia Política en América Latina puede leerse desde los cambios históricos de sus países. Los diferentes cambios de régimen, los movimientos sociales y la diferenciada llegada a la democracia explican en cierta medida los desarrollos particulares de la disciplina en cada país. Esta relación reconocida por ambos autores citados implica una nueva visión de la Ciencia Política que se diferencia del ideal behavorista, pero que 
se acerca más al entendimiento de los hechos políticos que suceden en América Latina.

En Colombia, específicamente, la Ciencia Política se funda bajo un hecho específico que se manifiesta en eventos diversos: el conflicto armado. Muchos de los programas, institutos y publicaciones primigenios de la disciplina nacen en orden a dar respuesta y analizar al latente conflicto que genera cambios estructurales en el país (Barrientos del Monte, 2013). Este hecho central dentro del desarrollo de la disciplina en Colombia marca una trayectoria clara que genera la estructuración de todo un entramado académico alrededor del tema que, como se dijo, necesariamente marca una posición política y, en general, análisis político que genera política. La suma de una visión mucho más política de la misma Ciencia Política y la importancia del contexto político en la creación del conocimiento en la disciplina inscribe este artículo en la necesidad de mostrar cómo un hecho del contexto político no sólo genera trabajos dentro de la disciplina sino que, además, estos trabajos tienen determinadas posiciones y perspectivas que en sí mismas son manifestaciones también políticas

Para el año 2003, luego de las elecciones presidenciales en Colombia, Álvaro Uribe Vélez llega al máximo cargo político mediante un discurso netamente enfocado en la concentración de energías en la terminación del conflicto y en el debilitamiento total de las guerrillas que casi cumplían un siglo de funcionamiento (Bushnell, 2007). Para el gobierno de Álvaro Uribe la política de Seguridad democrática se convirtió en la política bandera cuyo único fin era recuperar las libertades públicas soslayadas por los actos terroristas de grupos armados ilegales, como también el fortalecimiento de la soberanía del Estado, siendo el enfrentamiento de los grupos amados un compromiso claro (Plan Nacional de Desarrollo, 2006-2010).

Un hecho diciente de este cambio de perspectiva fue el aumento de los ataques contra las FARC realizándose 4.623 acciones bélicas del 2002 al 2009 (CINEP, 2010). Por otro lado, el pie de fuerza de las Fuerzas Militares aumento del 2002 al 2009, pasando de 313.361 miembros en el 2002 a 437.548 en 2009 (CINEP, 2010).

Para el segundo periodo de gobierno, se impuso la política de consolidación de la Seguridad Democrática. Durante este periodo aumento la presencia de fuerza pública en todos los municipios del país, pues en el 2002 al menos 168 del total de municipios estaban desprovistos de estaciones de policías y para el 2010 cada municipio tenía al menos 
una. (Ministerio de Defensa, 2010). Todos estos hechos estructuraron una política de ataque frontal contra los grupos al margen de la ley que cambiaría totalmente la visión del gobierno sobre el conflicto que se desarrollaba en el país.

Es por ello que la Ciencia Política, representada en los diferentes programas académicos e institutos de investigación, empieza a generar trabajos, estudios y análisis por la política que duraría más de 8 años. La pregunta que subyace a dicho planteamiento y que estructura el presente documento es de qué manera los años de la seguridad democrática fueron abordados por la Ciencia Política.

Por lo mismo, lo que quiere este texto es demostrar que Ciencia Política abordó el fenómeno político en contravía con el curso de los hechos, de tal manera que mientras la política de Seguridad Democrática propugnaba por un aumento en la ofensiva militar, la visión desde la Ciencia Política se concentraba en la manera de llegar a unos diálogos de paz o una salida concertada al conflicto.

\section{Metodología}

Planteado el tema y motivaciones del presente texto debe ponerse de manifiesto que la metodología escogida será el estudio de caso. Para Yin (2009) el estudio de caso tiene tres características esenciales: el hecho estudiado no está claramente diferenciado del contexto en el que nace, se utilizan múltiples fuentes para alimentar el estudio y su principal característica es que estudia un hecho en específico no de manera excluyente sino, más bien, teniendo en cuenta el contexto en el que este nace. En ese sentido, el caso de análisis escogido es el periodo de la "Seguridad Democrática" como se dijo anteriormente. Se escoge esta temporalidad por dos razones: primero, representa los dos periodos de gobierno más preponderantes en materia política en Colombia, no sólo por su duración, sino también por la importancia de sus políticas en materia de seguridad y defensa. Una segunda razón tiene que ver con la relación de este periodo con las negociaciones de paz con la guerrilla de las FARC en La Habana, cuyo proceso ha sido ejecutado por el otrora ministro de defensa de Álvaro Uribe y hoy presidente, Juan Manuel Santos.

El estudio de caso se alimenta directamente de una revisión de artículos académicos en cuatro revistas de Ciencia Política reconocidas por Publindex: Análisis Político, Colombia Internacional, Papel Político y Estudios Políticos. La búsqueda se realizó 
siguiendo los criterios establecidos frente a los temas de seguridad y, en general, de gobierno de los ocho años de gobierno de Álvaro Uribe Vélez. La presentación de resultados se hará mediante cinco tablas informativas presentadas a continuación.

\section{Tabla 1.}

Artículos encontrados respecto de la revista en los que se publicaron, los autores y el año de publicación

\begin{tabular}{|c|c|c|c|}
\hline Revista & Nombre del artículo & Autores & Año \\
\hline & & & \\
\hline
\end{tabular}

La Tabla 1 tiene como objetivo mostrar los artículos encontrados teniendo en cuenta la revista en la cual fue encontrado, el autor o autores del mismo y el año de publicación. Se adopta esta manera de mostrar de manera primigenia los datos pues contribuye a realizar una investigación de manera más transparente para con los resultados y, además, resulta oportuna en cuanto a presentación inicial de los hallazgos. La misma función tiene la Tabla 2 en la cual simplemente se ponen de manifiesto la cantidad de artículos respecto de las revistas revisadas.

\section{Tabla 2.}

Número de artículos encontrados por revista

\begin{tabular}{|l|l|}
\hline Revista & Número de artículos encontrados \\
\hline & \\
\hline
\end{tabular}

La característica esencial de las dos primeras tablas propuestas es que son de carácter netamente descriptivo. En ellas no se profundiza aún con respecto al contenido de los artículos y mucho menos cómo estos abordan el fenómeno escogido. La tabla 3, por el contrario, si entra directamente a indagar sobre los contenidos específicos que tienen los artículos respecto a su revisión.

\section{Tabla 3.}

Número de artículos por tema propuesto

\begin{tabular}{|c|c|c|c|c|c|c|}
\hline Revista & $\begin{array}{c}\text { Conflicto } \\
\text { Armado }\end{array}$ & $\begin{array}{c}\text { Seguridad } \\
\text { ciudadana }\end{array}$ & $\begin{array}{c}\text { Relaciones } \\
\text { Internacionales }\end{array}$ & $\begin{array}{c}\text { Relaciones } \\
\text { Ejecutivo- } \\
\text { legislativo }\end{array}$ & Economía & Otro \\
\hline & & & & & & \\
\hline
\end{tabular}


La Tabla 3 adquiere preponderancia en cuanto está diseñada para mostrar los temas centrales que la academia estudio respecto al Gobierno de Álvaro Uribe, bajo la creencia inicial que la Seguridad Democrática, como la misma política reconoce, va más allá de la ofensiva contra las FARC (República de Colombia, 2003). Además de ello también se logra dilucidar los temas relacionados que no se encuentran en la política como son el tema de las relaciones ejecutivo-legislativo y las relaciones internacionales. La tabla 4 analiza con más profundidad los artículos encontrados y detalla qué metodología usa para abordar el fenómeno escogido.

Tabla 4.

Número de artículos por metodología usada

\begin{tabular}{|c|c|c|c|c|c|c|}
\hline Revista & $\begin{array}{c}\text { Metodología } \\
\text { comparada }\end{array}$ & $\begin{array}{c}\text { Estudio de } \\
\text { caso }\end{array}$ & $\begin{array}{c}\text { Método } \\
\text { histórico }\end{array}$ & $\begin{array}{c}\text { Método } \\
\text { Estadístico }\end{array}$ & $\begin{array}{c}\text { Revisión } \\
\text { documental }\end{array}$ & Otro \\
\hline & & & & & & \\
\hline
\end{tabular}

La razón de ser de esta tabla es indagar por el cómo dichos artículos abordan la temática propuesta y bajo que parámetros metodológicos. Desde esa panorámica el análisis es mucho más general e incluyente en la medida que también analiza las cuestiones técnicas y de escritura de los artículos en sí mismos. Finalmente, la tabla 5 muestra la manera en que los artículos toman y manejan el tema dado por lo que se indaga por el manejo neutral del tema o se apoya o critica una posición determinada.

Tabla 5.

Número de artículos por manejo del tema propuesto

\begin{tabular}{|l|l|l|l|}
\hline Revista & Manejo Neutral & Crítica & Apoyo \\
\hline & & & \\
\hline
\end{tabular}

Esta última tabla resulta esencial pues es el resultado del análisis riguroso de los artículos en búsqueda de adjetivos específicos del o los autores hacia el tema tratado y de posiciones personales expresados en ellos en términos de críticas o apoyos. En ese sentido, para profundizar la hipótesis planteada se reconoce el concepto de artículos de orden "neutral" como aquellos que se limitan a describir el fenómeno sin proponer o tomar una posición en orden al contenido tópico del artículo. La variable "crítica" hace referencia 
a una posición negativa frente a lo planteado por la Seguridad Democrática y "apoyo" indica una posición de aceptación respecto de los temas tratados.

\section{Resultados}

A continuación se presentan las tablas ${ }^{2}$ ya descritas con los datos y hallazgos encontrados dentro del proceso de investigación. La tabla 1 muestra los artículos encontrados para las revistas Colombia Internacional, Análisis Político, Estudios Políticos y Papel Político.

En esta primera tabla pueden destacarse que la mayor cantidad de artículos sobre el tema se encuentran en las revistas de Análisis Político y de Colombia Internacional, dos de las más antiguas dentro de la academia colombiana. Este hecho queda confirmado en la Tabla 2 y en la Gráfica 1. Otra particularidad que puede verse dentro de los artículos encontrados es el número de artículos escritos por autores extranjeros que, sobretodo, se concentran en la revista Colombia Internacional. Este hecho, sumado a las cantidades totales ya expuestas, deja de manifiesto la tendencia de las revistas analizadas respecto al cómo se trata el tema y a qué autores corresponde dicho análisis.

\section{Tabla 1.}

Articulos, autores y fecha de publicación por revista

\begin{tabular}{|c|c|c|c|}
\hline Revista & Nombre del artículo & Autores & Año \\
\hline \multirow{5}{*}{ 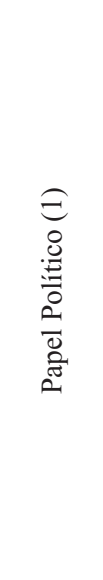 } & $\begin{array}{l}\text { Transformaciones Internas de las FARC a partir } \\
\text { de los cambios políticos por los que atraviesa el } \\
\text { Estado colombiano }\end{array}$ & $\begin{array}{l}\text { Aurora Moreno } \\
\text { Torres }\end{array}$ & Jul 2007 \\
\hline & $\begin{array}{l}\text { El problema mundial de las drogas ilícitas: su } \\
\text { efecto positivo en el crecimiento colombiano }\end{array}$ & Camila Pardo & Dic 2005 \\
\hline & $\begin{array}{l}\text { El desplazamiento forzado de colombianos hacia } \\
\text { Venezuela en el contexto de las prioridades de } \\
\text { Estados Unidos a la Región Andina }\end{array}$ & Consuelo Ahumada & Dic 2005 \\
\hline & $\begin{array}{l}\text { El desplazamiento forzado de colombianos y su } \\
\text { impacto sobre la frontera colombo-ecuatoriana } \\
\text { en el contexto del Plan Colombia: El caso de } \\
\text { Sucumbíos }\end{array}$ & $\begin{array}{l}\text { Consuelo Ahumada } \\
\text { y Álvaro Moreno }\end{array}$ & Dic 2003 \\
\hline & $\begin{array}{l}\text { Las Elecciones Presidenciales de } 2002 \text { en Co- } \\
\text { lombia: un esfuerzo explicativo }\end{array}$ & $\begin{array}{l}\text { Rodrigo Losada, } \\
\text { Fernando Giraldo y } \\
\text { Patricia Muñoz }\end{array}$ & Dic 2003 \\
\hline
\end{tabular}

2 La enumeración de las tablas repite ordén, ya que se corresponden la una con la otras. 


\begin{tabular}{|c|c|c|c|}
\hline Revista & Nombre del artículo & Autores & Año \\
\hline \multirow{8}{*}{ 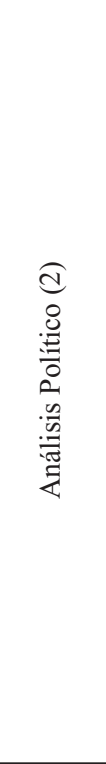 } & Una visión de la seguridad en Colombia & $\begin{array}{l}\text { Francisco Leal } \\
\text { Buitrago }\end{array}$ & $\begin{array}{l}\text { Sept-Dic. } \\
2011\end{array}$ \\
\hline & $\begin{array}{l}\text { Hacia una definición de experiencia civil de } \\
\text { construcción de paz en Colombia. }\end{array}$ & $\begin{array}{l}\text { Mauricio Hernandez } \\
\text { Perez }\end{array}$ & $\begin{array}{l}\text { Sept-Dic. } \\
2011\end{array}$ \\
\hline & $\begin{array}{l}\text { La política de consolidación de la seguridad } \\
\text { democrática: balance 2006-2008 }\end{array}$ & $\begin{array}{l}\text { Adolfo León Atehor- } \\
\text { túa y Diana Marcela } \\
\text { Rojas }\end{array}$ & $\begin{array}{l}\text { Mayo-Agosto } \\
2009\end{array}$ \\
\hline & La política de seguridad democrática: 2002-2005 & $\begin{array}{l}\text { Francisco Leal } \\
\text { Buitrago }\end{array}$ & $\begin{array}{l}\text { Mayo-Agosto } \\
2006\end{array}$ \\
\hline & $\begin{array}{l}\text { Conducta de la guerrilla durante el gobierno } \\
\text { Uribe Vélez: de las lógicas de control territorial a } \\
\text { las lógicas de control estratégico }\end{array}$ & $\begin{array}{l}\text { Camilo Echandia } \\
\text { Castilla y Eduardo } \\
\text { Bechara Gómez }\end{array}$ & $\begin{array}{l}\text { Mayo-Agosto } \\
2006\end{array}$ \\
\hline & $\begin{array}{l}\text { Proceso inconcluso, verdades a medias: para un } \\
\text { balance de las negociaciones del gobierno Uribe } \\
\text { con los paramilitares }\end{array}$ & Fernando Cubides & $\begin{array}{l}\text { Mayo-Agosto } \\
2006\end{array}$ \\
\hline & $\begin{array}{l}\text { La seguridad durante el primer año del gobierno } \\
\text { de Álvaro Uribe Vélez }\end{array}$ & $\begin{array}{l}\text { Francisco Leal } \\
\text { Buitrago }\end{array}$ & $\begin{array}{l}\text { Enero-Abril } \\
2004\end{array}$ \\
\hline & La seguridad: difícil de abordar con democracia & $\begin{array}{l}\text { Francisco Leal } \\
\text { Buitrago }\end{array}$ & $\begin{array}{l}\text { Mayo-Agosto } \\
2002\end{array}$ \\
\hline \multirow{6}{*}{ 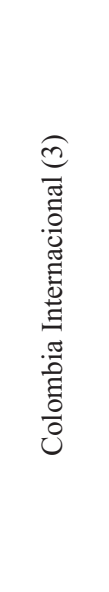 } & $\begin{array}{l}\text { En busca de aliados para la "Seguridad Demo- } \\
\text { crática" La política exterior del primer año de la } \\
\text { administración Uribe }\end{array}$ & $\begin{array}{l}\text { Arlene B. Tickner y } \\
\text { Rodrigo Pardo }\end{array}$ & $\begin{array}{l}\text { Sept. } 2002- \\
\text { Junio } 2003\end{array}$ \\
\hline & $\begin{array}{l}\text { La securitizacion de la crisis colombiana: bases } \\
\text { conceptuales y tendencias generales }\end{array}$ & Arlene B. Tickner & 2006 \\
\hline & La estrategia Uribe de negociación del TLC & Jorge Reinel Pulecio & $\begin{array}{l}\text { Enero-Junio } \\
2005\end{array}$ \\
\hline & ¿Sobrevivirá la coalición de Uribe? & $\begin{array}{l}\text { Santiago Olivella y } \\
\text { Cristina Vélez }\end{array}$ & Jul-Dic 2006 \\
\hline & $\begin{array}{l}\text { Efectos de la regionalización de la política de } \\
\text { seguridad democrática para el desplazamiento en } \\
\text { las fronteras de Colombia }\end{array}$ & $\begin{array}{l}\text { María Camila López } \\
\text { Rojas }\end{array}$ & $\begin{array}{l}\text { Enero-Junio } \\
\text { de } 2007\end{array}$ \\
\hline & $\begin{array}{l}\text { El espectáculo político del acuerdo humanita- } \\
\text { rio y la mediación de Hugo Chávez durante el } \\
\text { segundo mandato de Álvaro Uribe }\end{array}$ & $\begin{array}{l}\text { Manolo Constain y } \\
\text { Vladimir Rouvinski }\end{array}$ & Jul-Dic 2004 \\
\hline \multirow{2}{*}{ 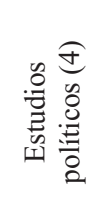 } & $\begin{array}{l}\text { "Guerra civil continuada por otros medios": } \\
\text { dimensiones normativas e ideológicas del cono- } \\
\text { cimiento científico- social e histórico en torno al } \\
\text { conflicto armado colombiano }\end{array}$ & $\begin{array}{l}\text { Paul Anthony } \\
\text { Chambers }\end{array}$ & $\begin{array}{l}\text { Enero-Junio } \\
2013\end{array}$ \\
\hline & $\begin{array}{l}\text { La política internacional de Estados Unidos y la } \\
\text { internacionalización del conflicto colombiano }\end{array}$ & $\begin{array}{l}\text { William Restrepo } \\
\text { Riaza }\end{array}$ & Jul-Dic 2004 \\
\hline
\end{tabular}

Fuente: elaboración propia. 


\section{Tabla 2.}

Número de artículos encontrados por revista

\begin{tabular}{|l|c|}
\hline \multicolumn{1}{|c|}{ Revista } & Número de artículos encontrados \\
\hline Papel Político (1) & 5 \\
\hline Análisis Político (2) & 8 \\
\hline Colombia Internacional (3) & 6 \\
\hline Estudios Políticos (4) & 2 \\
\hline
\end{tabular}

Fuente: elaboración propia.

Gráfica 1.

Número de articulos por revista

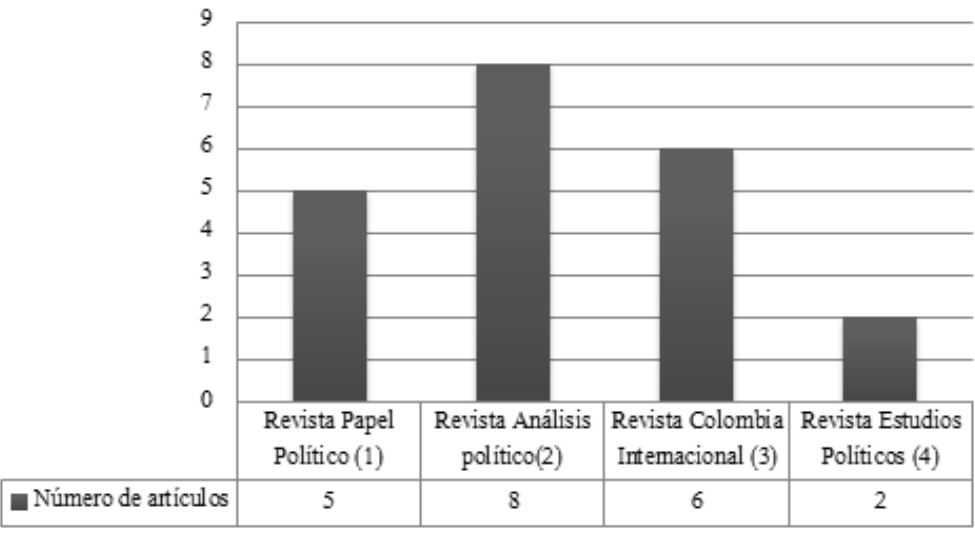

Fuente: elaboración propia.

Dada esta primera parte descriptiva de los resultados, se pueden sacar varias cuestiones iniciales. Primero, en las revistas seleccionadas se encontraron varios artículos sobre el tema, lo que pone de manifiesto la importancia del periodo dentro del ambiente académico y dentro de la construcción científica de dichos artículos. Segundo, no es un tema que sea tratado exclusivamente por nacionales dado que varios extranjeros determinan relevante el caso escogido. Finalmente, como tercera cuestión, queda en evidencia la preponderancia de las revistas Colombia Internacional y Análisis Político dentro del estudio del fenómeno político dada la cantidad de artículos que presentan sobre el tema.

En consonancia a todo lo anterior, y trascendiendo el análisis meramente descriptivo, la Tabla 3 muestra el número de artículos clasificados por el tema del cual tratan. 
Tabla 3.

Número de artículos por tema

\begin{tabular}{|c|c|c|c|c|c|c|}
\hline Revista & $\begin{array}{l}\text { Conflicto } \\
\text { Armado }\end{array}$ & $\begin{array}{l}\text { Seguridad } \\
\text { ciudadana }\end{array}$ & $\begin{array}{c}\text { Relaciones } \\
\text { Internacionales }\end{array}$ & $\begin{array}{l}\text { Relaciones } \\
\text { Ejecutivo- } \\
\text { legislativo }\end{array}$ & Economía & Otro \\
\hline 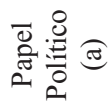 & 1 & & 1 & & 1 & $\begin{array}{c}2 \text { (elecciones } \\
\text { presidenciales) }\end{array}$ \\
\hline 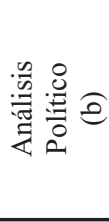 & 3 & & & & & $\begin{array}{c}3 \text { (seguridad y } \\
\text { democracia) } \\
1 \text { (construcción } \\
\text { de paz ) } \\
1 \text { (negociacio- } \\
\text { nes de paz) }\end{array}$ \\
\hline 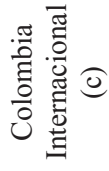 & & & 4 & 1 & & $\begin{array}{c}1 \text { (acuerdo } \\
\text { humanitario } \\
\text { y seguridad } \\
\text { democrática) }\end{array}$ \\
\hline 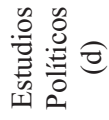 & 1 & & 1 & & & \\
\hline
\end{tabular}

Fuente: elaboración propia.

\section{Gráfica 2.}

Número de artículos clasificados por tema

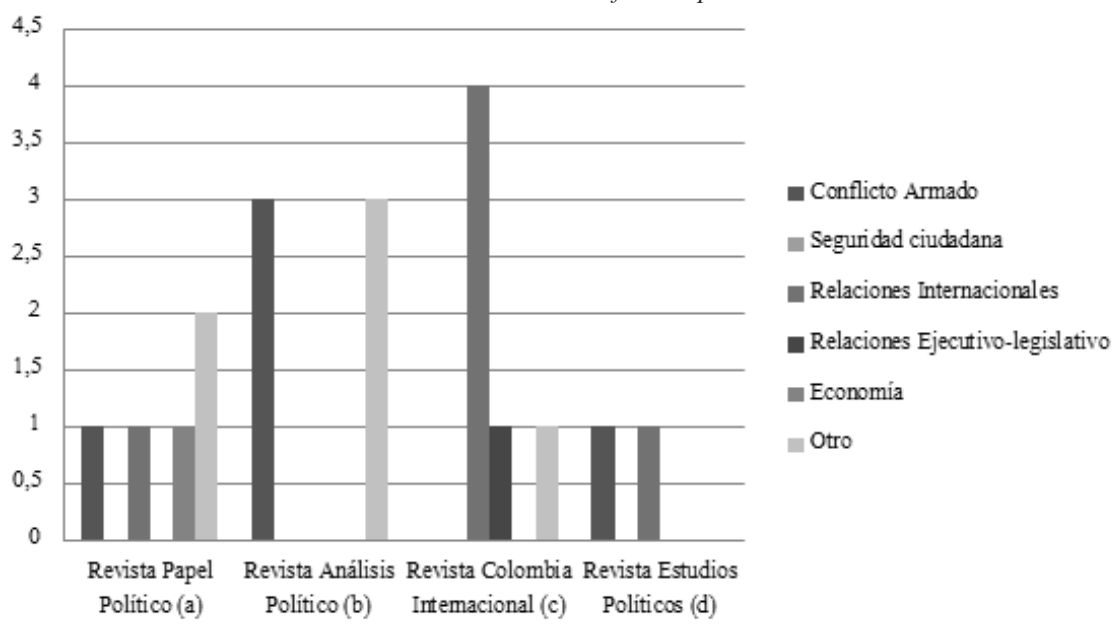

Fuente: elaboración propia. 
La tabla 3 junto con la gráfica 2 clarifica la cuestión temática dentro de los artículos encontrados. La primera información que puede observarse de dicha tabla es la clara preponderancia de los artículos en la categoría "otros" respecto a los diálogos de paz, las negociaciones de paz, la construcción de paz y los acuerdos humanitarios. Este hecho, visto a la luz de lo planteado al principio de este artículo, plantea una clara tendencia de los artículos en lo referente a la díada conflicto-paz y fin negociado-eliminación física de los grupos armados ilegales.

Otro tema preponderante dentro del análisis temático es la considerable cantidad de artículos que observan la cuestión de las Relaciones Internacionales dentro del gobierno de Álvaro Uribe y dentro de la política de Seguridad Democrático. Este hecho evidencia la importante dimensión internacional en el tema del conflicto armado, la lucha contra las drogas y la política exterior demarcada por el gobierno nacional. Transversalmente a lo dicho anteriormente, se evidencia que el tema clave dentro de la revisión es la cuestión relacionada con el conflicto armado que durante 50 años ha afectado al país en materia política, social y económica. No sorprende este hecho debido a que, como se dijo, la Seguridad Democrática aumentó drásticamente el pie de fuerza y las operaciones militares en el territorio nacional.

Dicho lo anterior, la Tabla 4 muestra el número de artículos encontrado en función a la metodología que se usa para analizar el fenómeno político en cuestión.

Junto con la gráfica 3, la tabla 4 muestra dos cuestiones concluyentes respecto a la metodología usada por los autores en la realización de los artículos encontrados. El estudio de caso y el método histórico son el tipo de metodologías predominantes dentro del análisis del hecho político escogido, lo que claramente determina, por un lado, la importancia del contexto en el periodo de tiempo y, por otro lado, la necesidad de utilizar variables históricas para analizar el tiempo y los procesos presentes.

La segunda conclusión que puede darse es lo llamativo que resulta que métodos como la metodología de orden comparado y el método estadístico no estén representados o ejecutados en ningún artículo. El método comparado y el método estadístico han sido considerados como centrales dentro de la Ciencia Política (Ángel Baquero y Barrero Escobar, 2013) y, sin embargo, se encuentra ausentes en los artículos encontrados, anotando que las revistas son clasificadas como de Ciencia Política por Publindex. 
Tabla 4.

Número de artículos por metodología usada

\begin{tabular}{|c|c|c|c|c|c|c|}
\hline Revista & $\begin{array}{l}\text { Metodología } \\
\text { comparada }\end{array}$ & $\begin{array}{l}\text { Estudio de } \\
\text { caso }\end{array}$ & $\begin{array}{c}\text { Método } \\
\text { histórico }\end{array}$ & $\begin{array}{c}\text { Método } \\
\text { Estadístico }\end{array}$ & $\begin{array}{c}\text { Revisión } \\
\text { documental }\end{array}$ & Otro \\
\hline 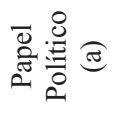 & & 5 & & & & \\
\hline 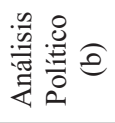 & & 5 & 3 & & & \\
\hline 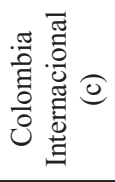 & & 6 & & & & \\
\hline 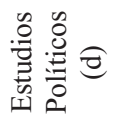 & & 1 & 1 & & & \\
\hline
\end{tabular}

Fuente: elaboración propia.

Gráfica 3.

Número de artículos por metodología usada

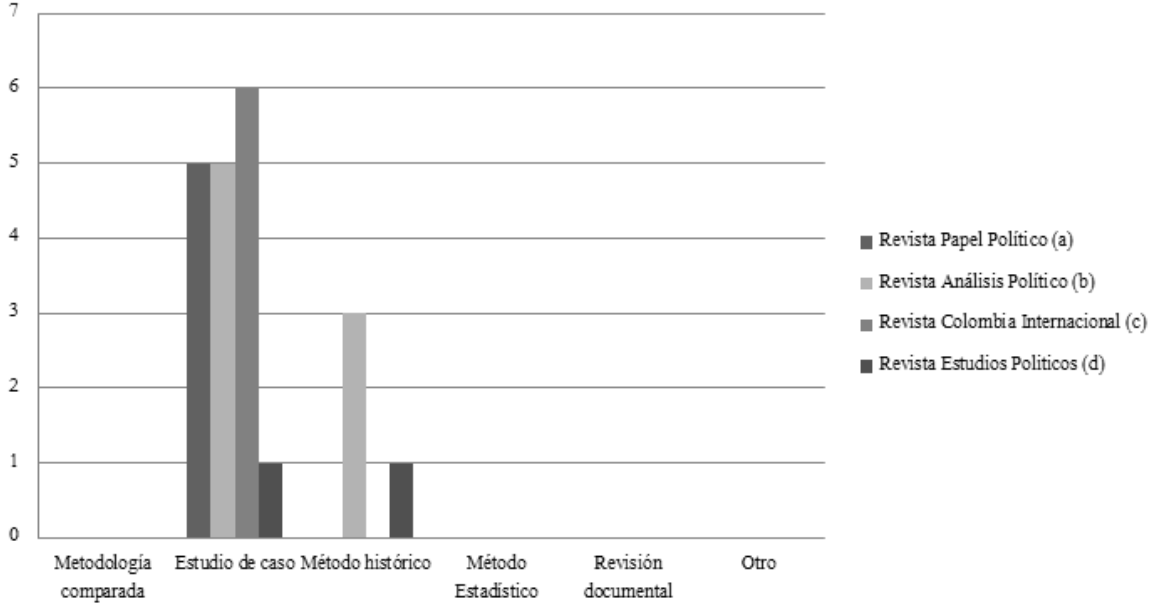

Fuente: elaboración propia. 
Finalmente, la tabla 5 muestra el número de artículos clasificados por su abordaje neutral o por hacer críticas o estar a favor de ciertas ideas o decisiones respecto del fenómeno político específico.

Lo que muestra la tabla 5 y la gráfica 4 se puede resumir en dos argumentos. Primero, sería evidente decir que por el carácter científico propio de los artículos, estos tienen una clara tendencia a manejar de manera neutral los temas e información plasmados en sus artículos. Esta afirmación resulta evidente dentro de la información propuesta, pero no resulta en una afirmación totalmente concluyente debido a la cantidad de artículos clasificados como críticas a ciertos temas o al general del proceso político

Tabla 5.

Número de artículos según orientación

\begin{tabular}{|l|c|c|c|}
\hline \multicolumn{1}{|c|}{ Revista } & Manejo Neutral & Crítica & Apoyo \\
\hline Papel Político (a) & 5 & & \\
\hline Análisis Político (b) & 2 & 6 & \\
\hline Colombia Internacional (c) & 3 & 3 & \\
\hline Estudios Políticos (d) & 2 & & \\
\hline
\end{tabular}

Fuente: elaboración propia.

Gráfica 4.

Número de artículos por orientación hacia el tema

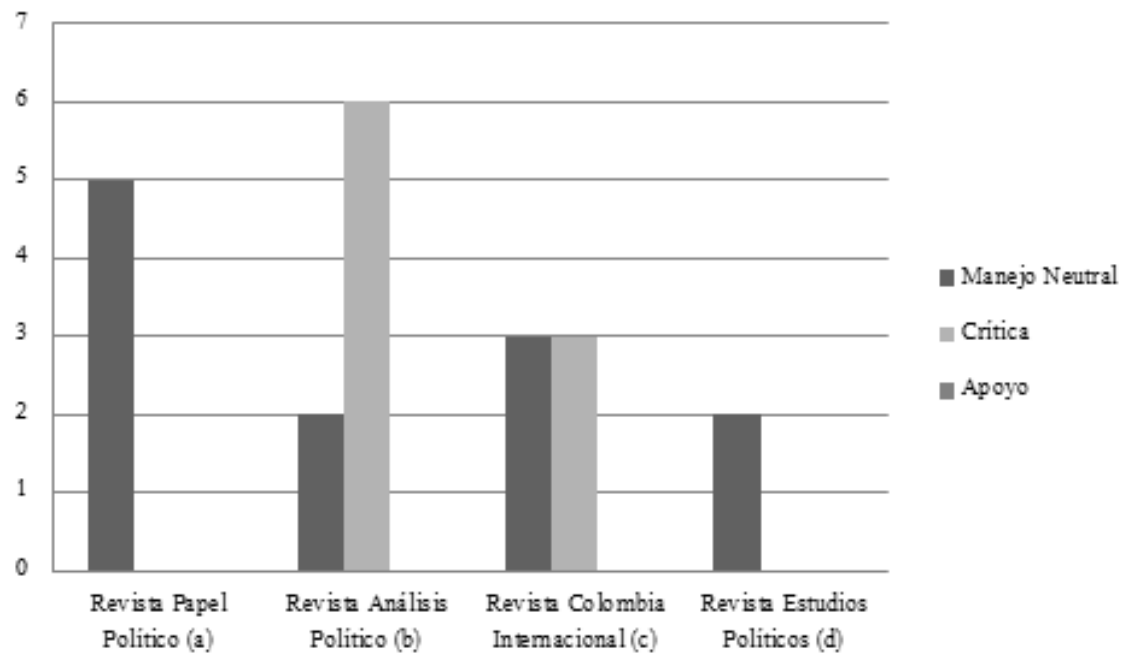

Fuente: elaboración propia. 
La segunda conclusión, por ende, son los artículos clasificados como "críticas" puestos allí por mostrar un posición determinada del autor o por el uso de adjetivos determinados dentro de las dos revistas más antiguas y de más publicaciones dentro de la revisión: Colombia Internacional y Análisis Político. Esta evidencia va en contra, como se dijo, del carácter netamente neutral que se esperaría de publicaciones académicas. Los artículos científicos también muestran tener posiciones de orden político. Además, muestra que el entendimiento del hecho político no sólo se limita al análisis sino también a la promulgación de determinadas posturas argumentadas y de diferentes posiciones frente a dicho fenómeno. Puede decirse, por tanto, que mientras el gobierno aumentaba su accionar militar, la academia formuló algunas críticas específicas a dicho hecho. La variable de "manejo neutral", además, muestra una coexistencia entre las posiciones de los autores y un intento de simplemente mostrar los hechos sin dar una interpretación o posición determinada como se adujo en la conceptualización inicial de este texto.

\section{Análisis de resultados: una mirada desde la literatura}

A partir de la evidencia mostrada anteriormente, se hace necesario un paneo de literatura teniendo siempre en cuenta las conclusiones que anteriormente se presentaron. Como se planteó inicialmente en el presente texto existe una relación problemática entre el desarrollo de la Ciencia Política y el estudio de los fenómenos políticos acontecidos dentro de un contexto social determinado.

En general, se ha formulado la cuestión referente a que el mismo hecho de generar conocimiento de lo político es en sí mismo un hecho político (Ravecca, 2010). En ese sentido, Rueschemeyer (2006) también aduce al hecho de que la importancia de las ideas que se plasman dentro de artículos de investigación crean e inducen a crear posiciones o generar escenarios de pensamiento colectivo.

Básicamente, la producción académica no está en función exclusiva de la ciencia, sino, también, de la sociedad en cuanto representa otra de las dimensiones del entramado político. Por lo mismo, se podría decir con base en la evidencia mostrada que la Seguridad Democrática, y en general el Gobierno de Álvaro Uribe, se convierte en un hecho relevante por dos razones. Primero, siguiendo a Rueschemeyer, por el hecho de 
figurar en cuatro de las revistas mejor calificadas en Publindex, el tema se convierte en socialmente relevante y crea un entramado ideológico dirigido a generar más conocimiento y establecer posiciones en cuanto a un fenómeno político. La segunda razón, siguiendo a Ravecca, es que el hecho de escribir sobre el tema determinado genera un hecho político en sí mismo, lo que hace más relevante aún la tabla correspondiente a la orientación seguida en los artículos.

Esta relación que puede establecerse entre la Ciencia Política y el contexto político incluso va más allá de la relación estudiante-estudiado. Barrientos del Monte (2013) en ese sentido, argumenta que en muchos casos el desarrollo de la Ciencia Política en América Latina se ve directamente influenciado por el tipo de gobierno en el cual tenga su aplicación. En varios países, por ejemplo, el tema del autoritarismo es clave para entender el desarrollo de la disciplina a nivel local. En Colombia, en términos generales, se ha identificado al conflicto armado como el gran tema estructurador de la Ciencia Política (Murillo Castaño y Ungar, 1999) y de varias Ciencias Sociales.

La anterior afirmación se ve reforzada, al menos, durante el periodo de gobierno de Álvaro Uribe Vélez dada la revisión temática de los artículos de investigación. Como se vio, las cuestiones del conflicto armado y de las negociaciones de paz son preponderantes dentro de la temática de la evidencia presentada. En ese sentido, se puede encontrar un argumento más para consolidar al conflicto armado como uno de los procesos políticos que más ha impactado dentro del desarrollo disciplinar de la Ciencia Política.

Ahora bien, desde el punto de vista de la metodología debe ampliarse el argumento referente a la existencia o no de un método propio o específico dentro de la Ciencia Política. Munck (2007) realiza un estudio a profundidad de las agendas de investigación en materia de Política Comparada en toda la región dejando de manifiesto que temas como los partidos políticos y las instituciones democráticas son las más estudiadas a la luz de esta metodología. Sin embargo, otro punto interesante del artículo es el reconocimiento de la Política Comparada como un método específico de la Ciencia Política. Frente a esta postura Angel y Barrero (2013) demuestran que no es posible identificar una metodología como propia de la Ciencia Política puesto que dentro de ella se ha condensado un crisol interdisciplinar en materia metodológica. 
A la luz de los datos encontrados, al menos en el caso escogido, se puede apreciar que ninguno de los artículos encontrados usó el método comparado para desarrollar la investigación. No compete a este artículo preguntarse por qué en dichos artículos no se utiliza el método comparado, pero sí puede decirse que el hecho de que predomine el estudio de caso y la metodología histórica da luces de cómo los procesos políticos son abordados por la Ciencia Política.

A partir de lo anterior y retomando lo dicho en un principio, tal vez la cuestión central de la evidencia presentada es la orientación encontrada en los artículos y los temas de los cuales se habla. Al menos de manera teórica, los grandes cambios sucedidos en la Ciencia Política durante el siglo XX lograron despojarla de su parcialidad, de la inferencia del autor en los datos y generó una ciencia en todo lo que esta categoría implica (Harto de Vera, 2005), (Olivella, 2007). Sin embargo, como se pudo apreciar en la revisión de los artículos gran parte de ellos se catalogaron como de manejo neutral, pero otro gran porcentaje se catalogó como crítica directa al fenómeno de orden político. Algunos artículos, ya fuera por alguna frase en específico o por el uso de adjetivos específicos, se salieron del parámetro científico citado y mostraron y defendieron una postura determinada.

Finalmente, debe decirse que como se aclaró la seguridad democrática fue caracterizada por un aumento en el pie de fuerza y en las acciones armadas, simultáneamente los artículos encontrados hacían una apología a la salida concertada del conflicto y a las negociaciones de paz, por lo que se puede decir que mientras el contexto político tenía una trayectoria definida, la Ciencia Política plasmada en los artículos científicos iba en contra del curso de los hechos realizando acercamientos alternativos y encaminados, muchas veces, a contradecir o criticar las políticas de gobierno.

\section{Conclusiones}

El periodo comprendido entre 2003 y 2010 estuvo caracterizado por el aumento en el pie de fuerza dentro de las Fuerzas Armadas de Colombia con la clara necesidad de subsanar definitivamente el problema de la insurgencia representada por grupos como las FARC o el ELN. Este periodo fue dirigido por el electo presidente Álvaro Uribe Vélez que imprimió un cambio enorme dentro del quehacer político, tanto así que su gobierno logró la aprobación de la reelección inmediata de la cual fue beneficiario. 
Después de realizar la búsqueda y sistematización de los artículos encontrados en las revistas Colombia Internacional, Análisis Político, Estudios Políticos y Papel Político se pueden generar varias conclusiones: primera, no sólo los autores colombianos abordan los procesos políticos del país. Segunda, las revistas más antiguas en la tradición académica en Colombia también fueron las más interesadas en publicar artículos referentes al proceso político escogido. Tercera, en materia temática predominaron los temas de conflicto armado, relaciones internacionales y de negociaciones de paz y salida concertada al conflicto armado.

Cuarto, una revisión de las metodologías usadas evidenció la inclinación a abordar el tema mediante el estudio de caso o mediante la metodología histórica, dejando de lado la metodología comparada y, quinta, si bien la mayoría de artículos tuvieron un manejo neutral de la temática, también una buena proporción de ellos generaron críticas a las políticas impulsadas por Álvaro Uribe sobretodo en términos de la seguridad democrática.

A partir de lo anterior, se parte del supuesto de que la creación de conocimiento sobre lo político genera ideas y hechos también políticos para decir que los artículos encontrados, de manera clara, generan y tienen posturas de orden político frente al fenómeno. En este caso, varios artículos generan críticas hacia la política de seguridad democrática, en específico, y hacia el gobierno de Álvaro Uribe en general.

Si a lo anterior se le suma el hecho de que además varios artículos realizan alusiones a la salida negociada del conflicto y a una paz generada de manera consensuada, se puede decir que, en realidad, la academia sí tuvo una particular aprehensión del hecho político en orden a analizarlo. Esta particularidad, como se vio con el análisis desde la literatura, va en contra de la visión clásica de la ciencia, pero muy en consonancia con nuevos análisis y teorías respecto de la forma como la Ciencia Política adopta, estudia y aborda un determinado proceso político.

A partir de todo lo anterior, se puede decir que la hipótesis resulta cierta en cuanto el contexto político de la época no está identificado o se desarrolla de la misma manera dentro de la academia, específicamente dentro de la Ciencia Política. En pocas palabras, la Ciencia Política abordó el fenómeno político en contravía con el curso de los hechos y mientras se aumentaba la ofensiva militar, los artículos académicos proponían salidas pacíficas del conflicto y, algo agregado a esta gran conclusión, que incluso se generaron críticas a cómo dichas políticas se ejecutaron. 


\section{Bibliografía}

ÁNGEL BAQUERO, S., y Barrero Escobar, F. A. (2013). La ciencia política y sus métodos: Una comparación de los programas de ciencias sociales en Colombia. Revista Co-Herencia, Volumen 10(Número 19).

BARRIENTOS DEL MONTE, F. (2013). La Ciencia Política en América Latina. Una breve introducción histórica. Convergencia. Revista de Ciencias Sociales, Vol 20(Núm 61), 105-133.

BARRIENTOS DEL MONTE, F. (2013). La Ciencia Política en América Latina. Una breve introducción histórica. Convergencia. Revista de Ciencias Sociales, Volumen 20(Número 61), $105-133$.

BUSHNELL, D. (2007). Colombia, una nación a pesar de sí misma (Primera edición). Bogotá: Planeta.

HARTO DE VERA, F. (2005). Ciencia Política Y Teoría Política Contemporánea: una relación problemática (Primera Edición). Madrid, España: Editorial Trotta.

MUNCK, G. (2007). Agendas y estrategias de investigación en el estudio de la política latinoamericana. Revista de Ciencia Política, Volumen 27(Número 1), 3-21.

MURILlO Castaño, G., y Ungar, E. (1999). Evolución y desarrollo de la Ciencia Política colombiana: Un proceso en marcha. Revista de Estudios Sociales, (Número 4), 36-57.

OLIVELLA, S. (2007). Del rigor en la Ciencia Política: algunas reflexiones sobre metodología de investigación. Colombia Internacional, (revista 66).

RAVECCA, P. (2010). La política de la Ciencia Política, ensayo de introspección disciplinar desde América Latina hoy. Revista América Latina, (9), 173-210.

REPÚBLICA DE COLOMBIA. (2003). Política de Defensa y Seguridad Democrática. Retrieved from http://www.oas.org/csh/spanish/documentos/Colombia.pdf

RUESCHEMEYER, D. (2006). Why and how ideas matter. In The Oxford Handbook of contextual political analysis (Primera edición). New york: Oxford University Press. 
VROMEN, A. (2010). Debating Methods: Rediscovering Qualitative Aproaches. In Marsh, D y Stoker, G, Theory and Methods in Political Science (pp. 249-267). Nueva York: Palgrave Macmillan.

YIN, R. (2009). Case Study Research, design and methods (Cuarta edición). New york: SAGE. 
